\title{
BMJ Open Sharp instrument injuries among hospital healthcare workers in mainland China: a cross-sectional study
}

\author{
Sheng-Li Huang, ${ }^{1,2}$ Qun Lu, ${ }^{3}$ Shan-Hong Fan, ${ }^{4}$ Zhi-Yong Zong, ${ }^{5}$ Tie-Ying Hou, ${ }^{6}$ \\ Bai-Yi Chen, ${ }^{7}$ Jin-Ai Qin, ${ }^{8}$ Yao Suo, ${ }^{1}$ Xiao-Dong Gao, ${ }^{9}$ Ning-Ning Wang ${ }^{1}$
}

To cite: Huang S-L, Lu Q,

Fan S-H, et al. Sharp instrument injuries among hospital healthcare workers in mainland China: a crosssectional study. BMJ Open 2017;7:e017761. doi:10.1136/ bmjopen-2017-017761

- Prepublication history and additional material are available. To view these files, please visit the journal online (http://dx.doi. org/10.1136/bmjopen-2017017761).

S-LH, QL and S-HF contributed equally.

Received 16 May 2017 Accepted 24 May 2017

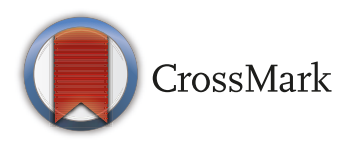

For numbered affiliations see end of article.

Correspondence to

Professor Yao Suo;

suoyaoxa1@163.comProfessor Xiao-Dong Gao;

gaoxd5@vip.sina.com and Dr

Ning-Ning Wang; ninglian2000@ 163.com

\section{ABSTRACT}

Objectives To determine the prevalence of sharp instrument injuries in hospital-based healthcare workers (HCWs) in mainland China and the contributing factors. Design Cross-sectional study.

Setting The data were derived from public hospitals. Participants A total of 360 hospitals were recruited in the study, including 289 general hospitals and 71 specialised hospitals. Among them, 194 are tertiary-level hospitals and 166 are secondary level. The study population finally consisted of 223149 hospital HCWs.

Primary outcome measures A questionnaire was designed based on the aim of the study. Profession of HCWs, workplace, circumstance and medical apparatus and instrument were covered in the survey. HCWs completed a self-administered questionnaire regarding details of sharp instrument injuries within the previous month. Prevalence estimates for the injuries were calculated for the overall HCWs and for subgroups according to profession, workplace, circumstance or instrument.

Results Within the included HCWs, the prevalence of sharp instrument injuries was 0.08 per person-month. Only $4.6 \%$ of the HCWs reported to their hospitals after injury. The highest number of injuries occurred in nursing staff (10.3\%). Injuries took place most frequently on general wards (44.5\%). The circumstances that involved most frequent injuries include surgical needle insertion, removing an arteriovenous needle from a patient and recapping the needle. Single-use syringe caused more injuries incidents than other instruments.

Conclusions These results indicate that sharp instrument injuries have become a major occupational problem of HCWs in mainland China. Attentions need to be paid to the issue and strategies for preventing such injuries are needed.

\section{INTRODUCTION}

Occupational exposure among healthcare workers (HCWs) has been gaining increasing attention in recent decades. ${ }^{1-8}$ HCWs are at risk of serious consequences from exposure to certain medical instruments. For example, most infections among medical staff can be attributed to occupational exposure, and the most commonly reported

\section{Strengths and limitations of this study}

- Our study assessed the prevalence of sharp instrument injuries in a representative sample of healthcare workers in mainland China.

- The study is the first nationally representative investigation of sharp instrument injuries among healthcare workers in developing countries.

- The primary limitation of this study is that the accuracy of the estimates of sharp instrument injuries was limited by the accuracy of recall of the participants.

routes are injuries due to contact with sharp instruments contaminated by blood or body fluids. ${ }^{9}$ Sharp instrument injuries, which are mostly preventable, jeopardise the safety of HCWs and represent a major occupational challenge. It is an important labour issue for HCWs in the world.

Sharp instrument injuries provide routes for transmission of pathogens such as hepatitis $\mathrm{B}$ virus (HBV), hepatitis $\mathrm{C}$ virus (HCV) and HIV, which result in bloodborne diseases. ${ }^{11} 12$ The incidence of exposure to bloodborne pathogens among HCWs has been studied in developed countries, ${ }^{2}$ but the concern remains largely ignored in developing countries. China is the world's largest developing country with the largest population and correspondingly a large body of medical staff who are facing occupational exposure on a daily basis. However, there are few reports of studies investigating sharp instrument injuries among HCWs in mainland China. Many of these studies ${ }^{13-17}$ were conducted on small sample sizes, involving a limited number of medical staff and/or covering a non-representative number of hospitals. This has limited the generalisability of the findings from these studies. To our knowledge, there is by far no large-scale study regarding sharp instrument injuries among HCWs in mainland China. The true prevalence of such injuries may have 
remained unknown. To address this gap in knowledge, a national prevalence survey covering a large number of hospitals in a wide range of areas was done in 2011.

\section{METHODS}

\section{Study design and participants}

This survey was a cross-sectional observational study. Since mainland China has various geographical regions and the prevalence rates of the injuries in different regions may be affected by local socioeconomic, traditional and rural or urban factors, a multistage stratified sampling method was employed to select a set of nationally representative samples of HCWs. First, one province was selected from each of the five large geographical regions in mainland China, namely northeast, northwest, southeast, southwest and south. The selected province was typical of a certain region in that no specialised policy or practice existed for public hospital administration. In addition, a municipality and an autonomous region were chosen to represent these two types of regions in mainland China. As a result, Shaanxi province, Sichuan province, Liaoning province, Zhejiang province, Guangdong province, Shanghai municipality and Guangxi Zhuang Autonomous Region were selected out of the 31 provinces, municipalities and autonomous regions in mainland China. These places were not sampled randomly but were chosen to span a range of medical care practices and socioeconomic conditions of the corresponding large regions, aiming to retain a nationwide geographic and social balance.

In the next stage, hospitals in each of the seven regions were selected using a stratified sampling based on their types and levels. In mainland China, hospitals are mainly classified as general and specialised in type and as tertiary and secondary in level. There are also a small number of community-level clinics, but they were not included in the survey due to the tiny portion they had accounted for in the whole medical care system in mainland China. In each province or autonomous region, we enrolled academic hospitals in the capital city and a local hospital from a smaller city or rural county. Hopefully, this sampling would generate reliable representation of the sharp instrument injuries among HCWs in Chinese medical system.

\section{Survey design}

We could rely on only self-reported data but not on objective observations. To minimise the recall bias, injuries to be reported were limited to those that had occurred within a month before the participants were surveyed. We focused on percutaneous injuries caused by at least one of the sharp medical devices in their work environment, including needle, lancet, scalpel, broken glass (excluding broken ampoule), and so on. All participants had the ability to answer a written questionnaire. It included two sections: the first section asked about the participant's name, department, occupation, knowledge training on occupational exposure and history of sharp instrument injuries in the past month, and the second section asked about the number of injuries having occurred within the past month, the involved devices, the procedures, the exact places of the reported incidents, information about exposure to blood and body fluids of patients, and so on. Multiple choice questions, with just one correct answer, were used to collect the information.

\section{Procedures}

The survey was conducted in three steps. First, written notifications were sent to the participating hospitals. The hospital-caused infection management officers then were recruited and trained for 1 week to serve as data collectors. The training was focused on survey management and interview techniques. Second, questionnaires were distributed in all hospital departments and collected within a 1-week period. All people in the departments, except those holding solely administrative positions, completed the first section of the questionnaire. Finally, people who had reported sharp instrument injuries were interviewed face to face and the second section of the questionnaire was filled out during the interviews. Data collection was completed in a month. The institutional review board of the Second Affiliated Hospital of Xi'an Jiaotong University provided review and ethics approval of the survey (no 2011112). All respondents were read a statement that explained the purpose of the survey. Written informed consent was obtained from each participant before data collection, and questionnaires were voluntarily completed and returned.

Sharp instrument injury has been defined as an injury caused by a sharp device which penetrates the skin. The instrument can be contaminated when it contacts with blood or body fluids of a patient. Exposure of intact skin or mucous membrane to bloodborne pathogens was not included in this study, so the participants were not to report the incidents of blood or body fluid splashing on intact skin. The knowledge or training on occupational exposure was hinted by the participants' report of attending postgraduate courses on occupational exposure to bloodborne pathogens and prevention of the infections. All participants were informed clearly that the exposure incidents they would report should have had occurred within the past month. Supervisors were responsible to review the questionnaires to ensure completion and accuracy.

\section{Statistical analysis}

The Mandarin version of EPINet (Exposure Prevention Information Network) was used for data entry and management. Analysis of the data was performed by the SPSS V17.0 software and using the descriptive statistic method. A two-sided $p$ value of 0.05 or less was regarded as of statistical significance. Categorical variables were expressed as percentages.

Professions of the participants were categorised as doctor, nurse, laboratory technician, sanitation worker (cleaners and medical waste collectors), student (interns 


\begin{tabular}{|c|c|c|c|c|c|}
\hline & \multirow[b]{2}{*}{ Total } & \multicolumn{2}{|l|}{$\begin{array}{l}\text { Tertiary } \\
\text { hospital }\end{array}$} & \multicolumn{2}{|c|}{$\begin{array}{l}\text { Secondary } \\
\text { hospital }\end{array}$} \\
\hline & & $\mathrm{n}$ & $\%$ & $n$ & $\%$ \\
\hline \multicolumn{6}{|l|}{ Hospitals } \\
\hline Total & 360 & 194 & 53.9 & 166 & 46.1 \\
\hline $\begin{array}{l}\text { General } \\
\text { hospital }\end{array}$ & 289 & 146 & 40.6 & 143 & 39.7 \\
\hline $\begin{array}{l}\text { Specialised } \\
\text { hospital }\end{array}$ & 71 & 48 & 13.3 & 23 & 6.4 \\
\hline \multicolumn{6}{|l|}{ Questionnaires } \\
\hline Total & 223149 & 161519 & 72.4 & 61630 & 27.6 \\
\hline $\begin{array}{l}\text { General } \\
\text { hospital }\end{array}$ & 193546 & 136475 & 61.2 & 57071 & 25.6 \\
\hline $\begin{array}{l}\text { Specialised } \\
\text { hospital }\end{array}$ & 29603 & 25044 & 11.2 & 4559 & 2.0 \\
\hline
\end{tabular}

and practical nurses) and other work (nursing assistants, laboratory attendants, mortuary attendants, ward orderlies, ambulance driver and other paramedical staff). The overall prevalence rate and the stratum-specific rates for various professions were calculated. The injuries were stratified according to workplace, circumstance and device. Workplace variables included blood drawing room and injection room for outpatients, outpatient clinic, emergency department, stomatology department, intensive care unit, haemodialysis unit, general ward, clinical laboratory, operating room and sterile processing centre, as well as room for temporarily disposing medical waste and others. The proportions of injury in terms of workplace were calculated in each of the six profession categories, and intergroup comparisons were performed using $\mathrm{X}^{2}$ test.

\section{RESULTS}

Altogether 360 hospitals were included in this study, among which 289 were general hospitals and 71 were specialised. Among them, 194 are tertiary-level hospitals and 166 are secondary level. A total number of 223149 full-time HCWs were included in the survey. The response rate was $100.0 \%$. Among these participants, 193546 $(86.8 \%)$ were from general hospitals, and 29603 (13.2\%) were from specialised hospitals (table 1 ).

In terms of profession categorisation, the survey population was composed of 63397 doctors (28.4\%), 106056 nurses $(47.5 \%), 10463$ laboratory technicians (4.7\%), 16415 sanitation workers $(7.4 \%), 15131$ students $(6.8 \%)$ and 11705 other workers (table 2). At the time of interview, approximately $88 \%$ of all participants across different professions had attended certain training programs about sharp injury prevention, except that around $25.9 \%$ of the students had not taken such training because they were at early stages of their education process and had not yet taken relevant courses. Incidence of sharp instrument




injuries was significantly different across professions $\left(\chi^{2}=6384, p=0.000\right)$, with nurses showing the highest prevalence $(92.8 \%)$.

A total of 18344 sharp instrument injuries were reported out of the 223149 participants. This translated into 8221 cases per 100000 HCWs for 1 month, or 0.08 per person-month. In other words, the incidence of sharp instrument injuries was $8.2 \%$. Some participants reported multiple injuries. Both the number of injuries and the number of injured individuals were documented. Table 2 displays the numbers of injuries as well as injured people in various profession categories. There were significant differences between professions $\left(\chi^{2}=1642, p=0.000\right)$. Nurses were identified to be the most vulnerable population to sharp object injuries. Incidents reported by this population accounted for 59.2\% of all the injuries documented in the survey. The incidence of injuries in nurses was $10.3 \%$, exceeding the $7.0 \%$ incidence in doctors. Students reported the largest proportion of injuries $(8.5 \%)$, followed by sanitation workers $(5.8 \%)$. Students had a higher reported incidence $\left(\chi^{2}=63.733, p=0.000\right)$ compared with other professions. Noticeably, among 14441 HCWs that had history of injury, less than $5 \%$ (4.6\%) claimed reporting of the incident.

Table 3 shows the distribution of HCWs in terms of profession and instruments contaminated with bloodborne pathogens. Of the 18344 reported injuries, 14208 $(77.5 \%)$ were caused by instruments used for patients with known infectious status. The rest $22.5 \%$ occurred during the disposal of sharp objects after using, which means that the sources of the injuries were unknown. The incidence of contact with bloodborne diseases was $6.7 \%$. Of these 1226 cases, $670(54.6 \%)$ involved a patient infected with $\mathrm{HBV}$ as source, $71(5.8 \%)$ involved a patient infected with HCV, $137(11.2 \%)$ had a patient infected with syphilis and $19(1.5 \%)$ had a patient infected with HIV. The remaining $329(26.8 \%)$ injuries involved patients with none of these four diseases at the time of exposure. The rate of injuries involving HBV, HCV, HIV and syphilis differed between doctors and nurses $\left(\chi^{2}=85.686, p=0.000\right)$.

Regarding workplaces where sharp instrument injuries occurred, general wards $(44.5 \%)$ were the most common places of occurrence, followed by operating rooms $(22.2 \%)$ (table 4$)$. Nearly two-thirds $(65.3 \%)$ of the injuries in doctors had occurred in operating rooms, and more than half $(58.3 \%)$ of those in nurses had occurred in medical wards.

Of all the incidents, $12.1 \%$ occurred during surgical needle insertion, $11.2 \%$ during removing an arteriovenous needle, $10.7 \%$ during recapping of used needles, $9.0 \%$ during handling of medical waste, $8.7 \%$ during preparing solution and $8.4 \%$ during discarding used needles into a container (table 4 and online supplementary table 1 ). The device that caused the highest proportion of injuries was single-use syringe needle (35.2\%), followed by scalp wire needle (23.3\%) and surgical suture

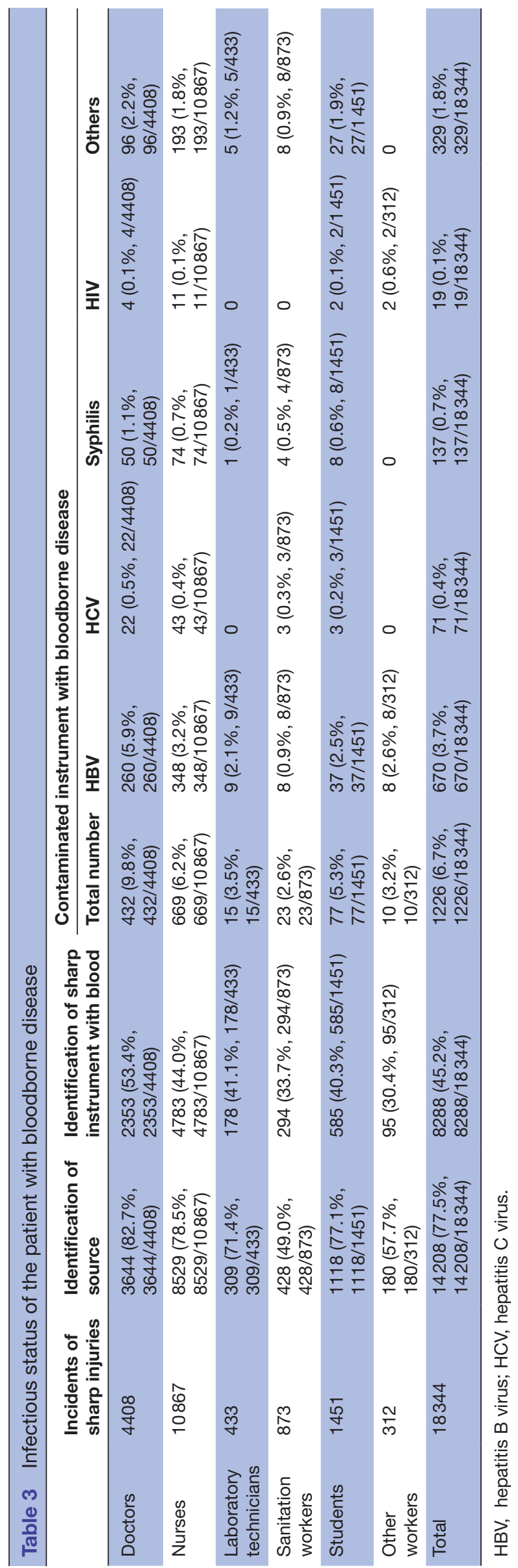




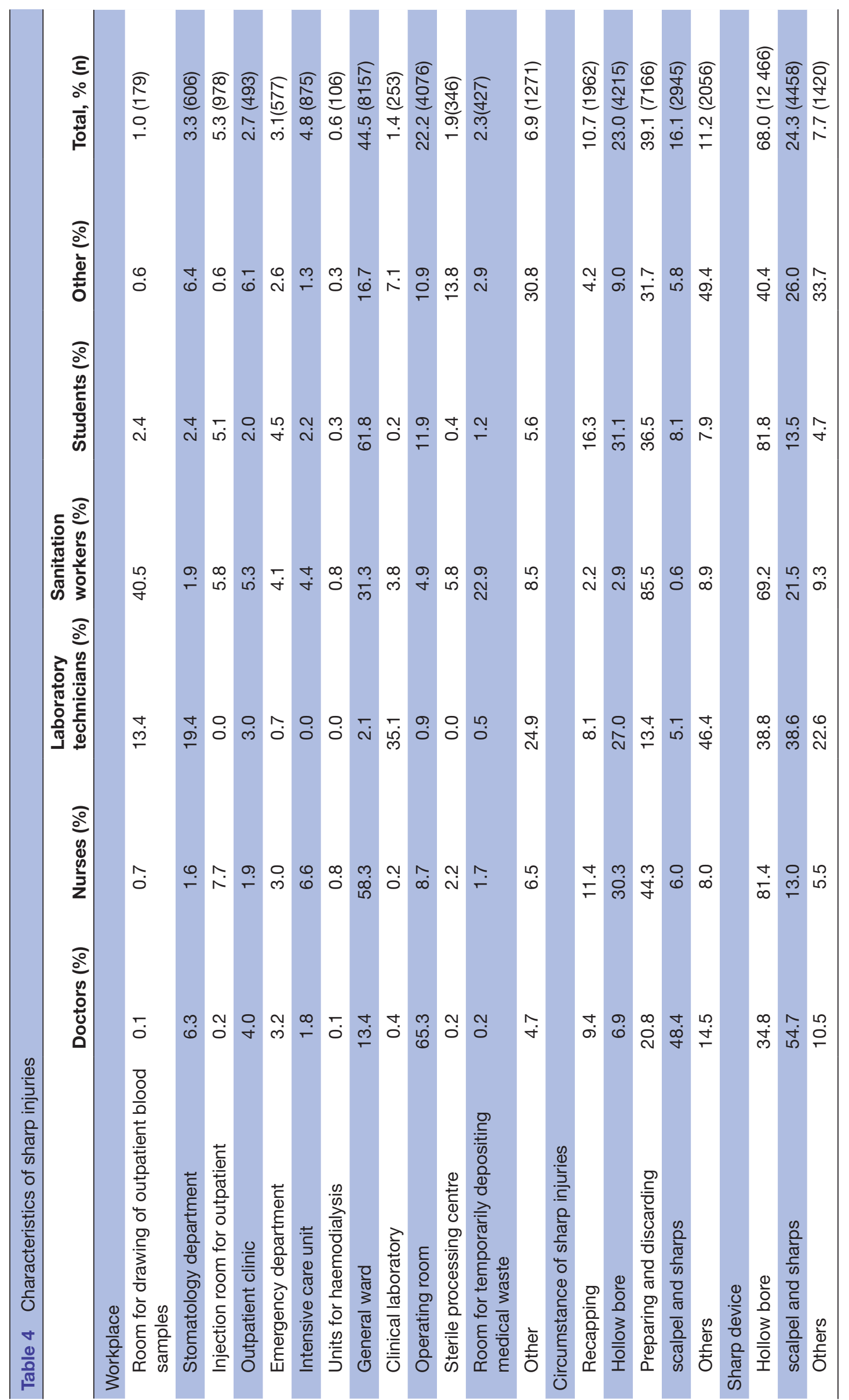


needle (14.0\%) (table 4 and online supplementary table 2).

\section{DISCUSSION}

Among the Chinese HCWs involved in this survey, the incidence of sharp instrument injuries is $8.2 \%$, while the rate of reported incidents is $0.1 \%$. The rate of reporting an incident is extremely low. Professional activity is identified to be a predisposing factor for sharp instrument injuries. Nurses appear to be the most vulnerable population, followed by students who face a higher risk of the injuries than all other professions except nurses. This survey, covering different geographical regions, types and levels of hospitals, professions, workplaces and contexts of incidents and instruments, has uncovered the current situation and added insight into the epidemiology of sharp instrument injuries in mainland China. Furthermore, the data from China, the world's largest developing country, provide valuable information for depicting these occupational hazards encountered by HCWs worldwide.

One characteristic of this study is the representativeness of the samples included. The survey involved altogether 223149 HCWs, forming a comparatively large sample size. The participates were drawn from places representative of different geographical regions and from a diversity of hospitals that are typical in Chinese healthcare system. It has been indicated in some previous studies that the prevalence of sharp instrument injuries differs substantially between geographical regions in mainland China. ${ }^{13-17}$ However, the regional data documented in most of these studies cannot be compared directly owing to differences in methods of sampling and criteria for defining sharp instrument injury. Compared with these studies, the present study is based on a large, comprehensive and representative sample, and the findings therefore more accurately reflect the current status of sharp instrument injuries in mainland China.

Some participants in our survey reported multiple incidents of injury, which is consistent with those reported elsewhere. $^{2}$ Nurses were the occupational group with the highest incidence of injuries, as reported similarly in other studies. ${ }^{18-20}$ It is not uncommon that nurses get injured repeatedly within a short period of time. This may be attributed to the nature of their jobs. They contact with sharp devices directly and frequently in their daily duties. The fact that the lowest prevalence was found in laboratory technicians helps prove this. The technicians have less touch with sharp instruments in their work than other profession groups do. In this study, students presented a high incidence of injuries (only lower than nurses) and a low rate of learning or training on occupational exposure. This is in conformity with the findings in previous studies that students face high risk of sharp instrument injuries owing to their lack of training and experience. ${ }^{6} 132122$ Therefore, training programs on prevention of such injuries among students seem necessary and beneficial. ${ }^{23}$
Transmission of bloodborne diseases has long been recognised as a potential threat to the health of HCWs. HCWs have a high probability of exposure to bloodborne pathogens due to sticks or cuts from sharp instruments contaminated with the blood of infected patients. ${ }^{24} \mathrm{HBV}$, $\mathrm{HCV}$ and HIV are some of the most serious bloodborne infections transmitted by sharp instrument injuries. In mainland China, the seroprevalence of HBV infection ranges from $6 \%$ to $8 \%$ of the population, ${ }^{25-28} \mathrm{HCV}$ has a prevalence of $3 \%{ }^{26}$ and the prevalence of HIV is rapidly rising. ${ }^{29}$ Syphilis is also prevalent in mainland China. ${ }^{30}$ All these four infections were included in this survey. The rates of injuries involving HBV, HCV and HIV documented in our survey are lower than those in Shiao's report, ${ }^{5}$ but this might be due to the low incidences of these diseases in mainland China. Still, our results have confirmed the threat of these infections to HCWs and remind us of the necessity of dealing with the transmission of these diseases through sharp instrument injuries. Supposedly, improving knowledge about occupational exposure and practice should contribute to reducing the spread of bloodborne diseases among HCWs. However, most HCWs in mainland China attended lecture-based training sessions usually without or with very limited demonstration and/or practice. This type of training is not sufficient for medical staff to gain sound knowledge of occupational exposure, and this does not offer them opportunities for hands-on practice. An implication of this situation is that implementation of infection control strategies and procedures needs attention particularly in developing countries.

Reporting and documenting incidents is one of the basic steps to preventing infectious diseases. ${ }^{19}$ Lack of reporting of exposure increases the likelihood of infection. In developed contraries, $58 \%$ of such injuries are reported. ${ }^{31}$ The reporting rate in Taiwan, China, is $21.2 \%{ }^{4}$ However, only less than $5 \%$ of the HCWs in our study reported their injuries; more than $95 \%$ of the incidents were unknown or ignored since they were not reported. Further research is needed to explore the reasons why HCWs do not report exposures and what can be done to improve the situation. Our study suggests a need of establishing a national surveillance system for occupational exposure to sharp instrument injuries in mainland China.

Based on our survey, the incidence of sharp instrument injuries varied across workplaces. The general ward was identified to be the most common place of occurrence, followed by operating room, injection room for outpatient and intensive care units. Similar with that reported in other studies, ${ }^{32-34}$ most of the reported injuries in this survey had taken place in the general ward, and the main reason should be the higher number of invasive interventions. Most incidents occurred during surgical needle insertion, recapping of used needles or removing an arteriovenous needle from a patient. The circumstances involving sharp instrument injuries differed markedly. In our study, approximately $50 \%$ of the reported accidents had occurred while working with or dealing with needles. 
The devices that most commonly caused injuries were single-use syringes, scalp wire needles and suture needles. These findings conform to the results of some studies that a large portion of sharp instrument injuries is caused by disposable syringes with needles. ${ }^{35} 36$

From the perspective of public health, investigation of the presence of sharp instrument injuries in HCWs is important to the prevention of such injuries. As there are about six million physicians and nurses in mainland China, sharp instrument injuries pose a serious occupational problem. Many developed countries follow universal precautions including using protective gloves, masks and eyewear. In mainland China, issues such as potential occupational burden due to such injuries must be considered, and actions need to be taken to prevent injuries in the process of patient care and treatment.

In mainland China, staff in public hospitals usually do not refuse to respond to healthcare studies proposed by the government. This survey was organised by the Ministry of Health, and the response rate was $100 \%$. To ensure privacy, names of the participants were kept confidential. There were no penalties or rewards for participation.

This study had some limitations. First, the data were collected retrospectively through participants recalling their experience in the past. The participants' memory might not be accurate, which in turn could influence the accuracy of the research results. It is likely that some participants might forget to report their injuries and this under-reporting would cause the documented number of incidents lower than the actual number. Second, even though we tried hard to select samples from various regions, selection bias could not be completely avoided and the included participants might not satisfactorily represent the body of HCWs in mainland China. Third, only hospitals were included in this study, which may not be able to represent the overall healthcare settings in mainland China. Smaller, lower-level, special and private clinics were left out. Fourth, traditional cultural differences in HCWs may be responsible for some discrepancies. Chinese nurses also perform tasks such as cleaning reusable medical equipment, which are generally done by ancillary personnel in the USA.

\section{CONCLUSIONS}

The high prevalence of sharp instrument injuries in HCWs in mainland China indicates that such injuries should not be neglected as they represent a significant cause of bloodborne infections in the workplace. Attention should be paid to unreported injury incidents. This finding is very worrisome and indicates the need for further action, such as improving the education/training programme, promoting universal precautions, increasing awareness of the seriousness, and so on.

\section{Author affiliations}

${ }^{1}$ Department of Infection Control, Second Affiliated Hospital, Xi'an Jiaotong University, Xi'an, China
${ }^{2}$ Department of Orthopeadics, Second Affiliated Hospital, Xi'an Jiaotong University, Xi'an, China

${ }^{3}$ Department of Infection Control, Second Affiliated Hospital of Zhejiang University, Hangzhou, China

${ }^{4}$ Department of Infection Control, Tangdu Hospital, Fouth Military Medical University, Xi'an, China

${ }^{5}$ Department of Infection Control, West China Hospital, Sichuan University, Chengdu, China

${ }^{6}$ Department of InfectionControl, Guangdong General Hospital, Guangzhou, China

${ }^{7}$ Department of Infection Control, First Hospital of China Medical University, Shenyang, China

${ }^{8}$ Department of Infection Control, First Affiliated Hospital of Guangxi Medical University, Nanning, China

${ }^{9}$ Department of Infection Control, Zhongshan Hospital, Fudan University, Shanghai, China

Acknowledgements We thank healthcare workers and the project staff for their strong collaboration and great effects made in the study.

Contributors S-LH searched the literature, analysed the data, interpreted the results and drafted the report. QL and S-HF searched the literature, analysed the data and interpreted the results. Z-YZ, T-YH, B-YC and J-AQ analysed the data and interpreted the results. YS and X-DG conceived the study, designed the study, supervised the study, interpreted the results and revised the report. N-NW analysed the data, interpreted the results and revised the report. S-LH, QL and S-HF contributed equally.

Competing interests None declared.

Patient consent Obtained.

Ethics approval Institutional review board of the Second Affiliated Hospital of Xi'an Jiaotong University.

Provenance and peer review Not commissioned; externally peer reviewed. Data sharing statement No additional data are available.

Open Access This is an Open Access article distributed in accordance with the Creative Commons Attribution Non Commercial (CC BY-NC 4.0) license, which permits others to distribute, remix, adapt, build upon this work non-commercially, and license their derivative works on different terms, provided the original work is properly cited and the use is non-commercial. See: http://creativecommons.org/ licenses/by-nc/4.0/

(c) Article author(s) (or their employer(s) unless otherwise stated in the text of the article) 2017. All rights reserved. No commercial use is permitted unless otherwise expressly granted.

\section{REFERENCES}

1. Prüss-Ustün A, Rapiti E, Hutin Y. Estimation of the global burden of disease attributable to contaminated sharps injuries among healthcare workers. Am J Ind Med 2005;48:482-90.

2. Clarke SP, Schubert M, Körner T. Sharp-device injuries to hospital staff nurses in 4 countries. Infect Control Hosp Epidemiol 2007;28:473-8.

3. Rice BD, Tomkins SE, Ncube FM. Sharp truth: health care workers remain at risk of bloodborne infection. Occup Med 2015;65:210-4.

4. Shiao JS, McLaws ML, Lin MH, et al. Chinese EPINet and recall rates for percutaneous injuries: an epidemic proportion of underreporting in the Taiwan healthcare system. J Occup Health 2009;51:132-6.

5. Shiao J, Guo L, McLaws ML. Estimation of the risk of bloodborne pathogens to health care workers after a needlestick injury in Taiwan. Am J Infect Control 2002;30:15-20.

6. Shiao JS, Mclaws ML, Huang KY, et al. Student nurses in Taiwan at high risk for needlestick injuries. Ann Epidemiol 2002;12:197-201.

7. Shiao JS, McLaws ML, Huang KY, et al. Sharps injuries among hospital support personnel. J Hosp Infect 2001;49:262-7.

8. Shiao JS, McLaws ML, Huang KY, et al. Prevalence of nonreporting behavior of sharps injuries in taiwanese health care workers. Am J Infect Control 1999;27:254-7.

9. Wilburn SQ, Eijkemans G. Preventing needlestick injuries among healthcare workers: a WHO-ICN collaboration. Int J Occup Environ Health 2004;10:451-6.

10. Osborn EH, Papadakis MA, Gerberding JL. Occupational exposures to body fluids among medical students. A seven-year longitudinal study. Ann Intern Med 1999;130:45-51. 
11. Riddell LA, Sherrard J. Blood-borne virus infection: the occupational risks. Int J STD AIDS 2000;11:632-9.

12. Dement JM, Epling C, Ostbye T, et al. Blood and body fluid exposure risks among health care workers: results from the Duke Health and Safety Surveillance System. Am J Ind Med 2004;46:637-48.

13. Yao WX, Yang B, Yao C, et al. Needlestick injuries among nursing students in China. Nurse Educ Today 2010;30:435-7.

14. Tang PF, Jamulitrat S, Chongsuvivatwong V, et al. Incidence and risk factors for sharps injury among healthcare workers in three hospitals in Kunming, China. J Nurs Sci 2009;27:42-8.

15. Smith DR, Wei N, Zhang YJ, et al. Needlestick and sharps injuries among a cross-section of physicians in Mainland China. Am J Ind Med 2006;49:169-74.

16. Phipps W, Honghong W, Min Y, et al. Risk of medical sharps injuries among chinese nurses. Am J Infect Control 2002;30:277-82.

17. Zhang $\mathrm{M}$, Wang $\mathrm{H}$, Miao J, et al. Occupational exposure to blood and body fluids among health care workers in a general hospital, China. Am J Ind Med 2009;52:89-98.

18. Bekele T, Gebremariam A, Kaso M, et al. Factors associated with occupational needle stick and sharps injuries among hospital healthcare workers in Bale Zone, Southeast Ethiopia. PLoS One 2015;10:e0140382.

19. Becirovic S, Pranjic N, Sarajlic-Spahic S, et al. Assessment of reporting, attitudes and knowledge about the stab incidents and professional risk of viral infection among health care professionals in primary health care. Mater Sociomed 2013;25:113-7.

20. Khuri-Bulos NA, Toukan A, Mahafzah A, et al. Epidemiology of needlestick and sharp injuries at a university hospital in a developing country: a 3-year prospective study at the Jordan University Hospital, 1993 through 1995. Am J Infect Control 1997;25:322-9.

21. Shen C, Jagger J, Pearson RD. Risk of needle stick and sharp object injuries among medical students. Am J Infect Control 1999;27:435-7.

22. Patterson JM, Novak CB, Mackinnon SE, et al. Needlestick injuries among medical students. Am J Infect Control 2003;31:226-30.

23. Yang YH, Liou SH, Chen CJ, et al. The effectiveness of a training program on reducing needlestick injuries/sharp object injuries among soon graduate vocational nursing school students in southern Taiwan. J Occup Health 2007;49:424-9.

24. Wong KC, Leung KS. Transmission and prevention of occupational infections in orthopaedic surgeons. J Bone Joint Surg Am 2004;86A:1065-76.
25. Liu J, Zhang S, Wang Q, et al. Seroepidemiology of hepatitis B virus infection in 2 million men aged 21-49 years in rural China: a population-based, cross-sectional study. Lancet Infect Dis 2016;16:80-6.

26. Zhang Q, Qi W, Wang X, et al. Epidemiology of hepatitis B and hepatitis $C$ infections and benefits of programs for hepatitis prevention in Northeastern China: a cross-sectional study. Clin Infect Dis 2016;62:305-12.

27. Liang X, Bi S, Yang W, et al. Epidemiological serosurvey of hepatitis $B$ in China-declining HBV prevalence due to hepatitis $B$ vaccination. Vaccine 2009;27:6550-7.

28. Lu J, Zhou Y, Lin X, et al. General epidemiological parameters of viral hepatitis $A, B, C$, and $E$ in six regions of China: a cross-sectional study in 2007. PLoS One 2009;4:e8467.

29. Zhang L, Chow EP, Jing J, et al. HIV prevalence in China: integration of surveillance data and a systematic review. Lancet Infect Dis 2013;13:955-63.

30. Tucker JD, Chen XS, Peeling RW. Syphilis and social upheaval in China. N Engl J Med 2010;362:1658-61.

31. Winchester SA, Tomkins S, Cliffe S, et al. Healthcare workers' perceptions of occupational exposure to blood-borne viruses and reporting barriers: a questionnaire-based study. J Hosp Infect 2012;82:36-9.

32. Ilhan MN, Durukan E, Aras E, et al. Long working hours increase the risk of sharp and needlestick injury in nurses: the need for new policy implication. J Adv Nurs 2006;56:563-8.

33. Azap A, Ergönül O, Memikoğlu KO, et al. Occupational exposure to blood and body fluids among health care workers in Ankara, Turkey. Am J Infect Control 2005;33:48-52.

34. Fisman $D N$, Harris $A D$, Rubin $M$, et al. Fatigue increases the risk of injury from sharp devices in medical trainees: results from a casecrossover study. Infect Control Hosp Epidemiol 2007;28:10-17.

35. Smith DR, Choe MA, Jeong JS, et al. Epidemiology of needlestick and sharps injuries among professional korean nurses. J Prof Nurs 2006;22:359-66.

36. Memish ZA, Assiri AM, Eldalatony MM, et al. Risk analysis of needle stick and sharp object injuries among health care workers in a tertiary care hospital (Saudi Arabia). J Epidemiol Glob Health 2013;3:123-9. 